\title{
Recommendations on Implementing the Energy Conservation Building Code in Rajasthan, India
}

$\mathrm{S} \mathrm{Yu}$

E Makela

M Evans

J Mathur*

*Malaviya National Institute of Technology Jaipur, India

February 2012

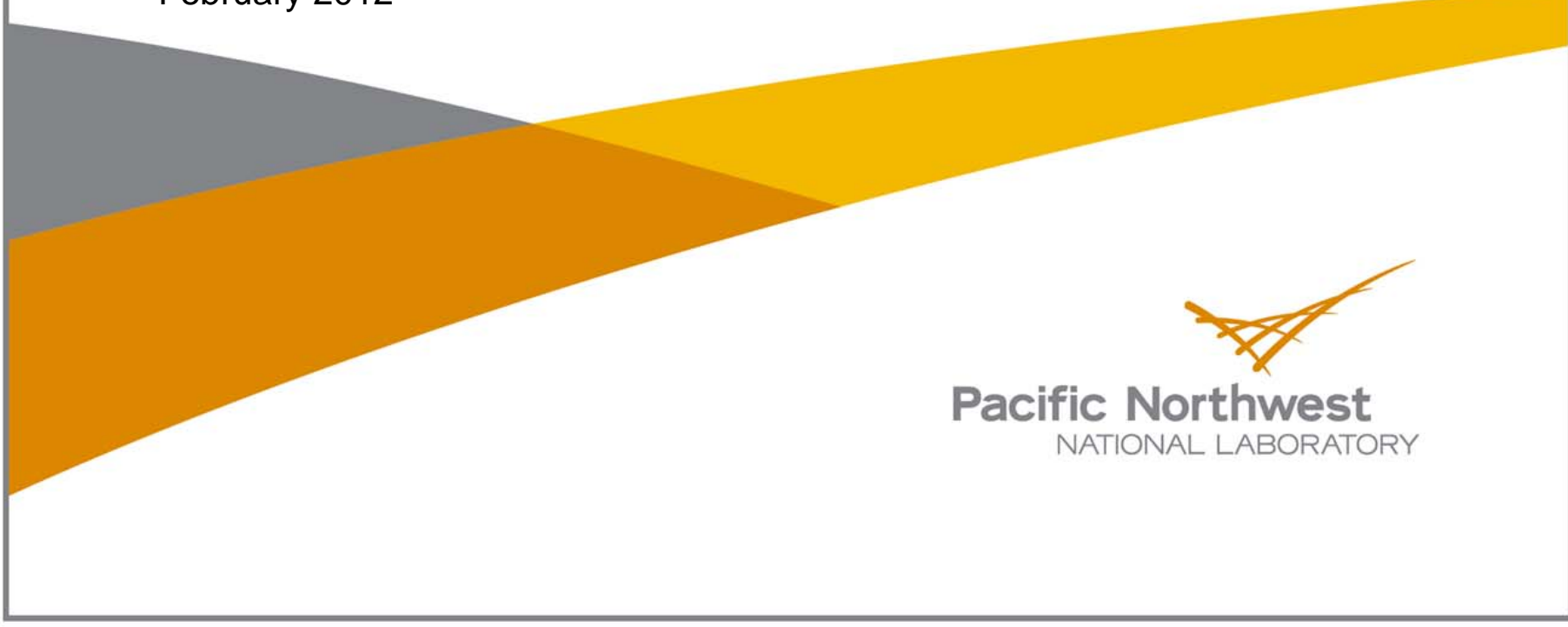





\title{
DISCLAIMER
}

This report was prepared as an account of work sponsored by an agency of the United States Government. Neither the United States Government nor any agency thereof, nor Battelle Memorial Institute, nor any of their employees, makes any warranty, express or implied, or assumes any legal liability or responsibility for the accuracy, completeness, or usefulness of any information, apparatus, product, or process diselosed, or represents that its use would not infringe privately owned rights. Reference herein to any specific commercial product, process, or service by trade name, trademark, manufacturer, or otherwise does not necessarily constitute or imply its endorsement, recommendation, or favoring by the United States Government or any agency thereof, or Battelle Memorial Institute. The views and opinions of authors expressed herein do not necessarily state or reflect those of the United States Government or any agency thereof.

\author{
PACIFIC NORTHWEST NATIONAL LABORATORY \\ operated by \\ BATTELLE \\ for the \\ UNITED STATES DEPARTMENT OF ENERGY \\ under Contract DE-AC05-76RL01830
}

Printed in the United States of America

Available to DOE and DOE contractors from the

Office of Scientific and Technical Information,

P.O. Box 62, Oak Ridge, TN 37831-0062;

ph: (865) 576-8401

fax: (865) 576-5728

email: reports@adonis.osti.gov

\author{
Available to the public from the National Technical Information Service, \\ U.S. Department of Commerce, 5285 Port Royal Rd., Springfield, VA 22161 \\ ph: (800) 553-6847 \\ fax: (703) 605-6900 \\ email: orders@ntis.fedworld.gov \\ online ordering: http://www.ntis.gov/ordering.htm
}

This document was printed on recycled paper.

(9/2003) 



\section{Contents}

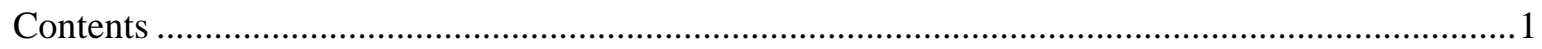

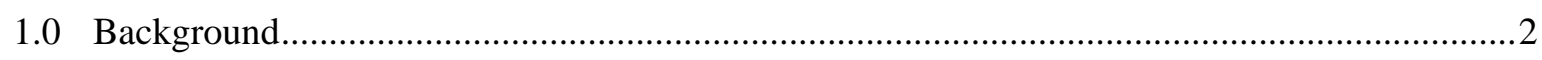

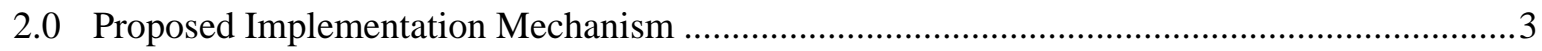

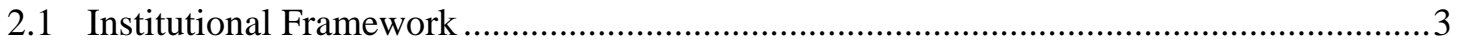

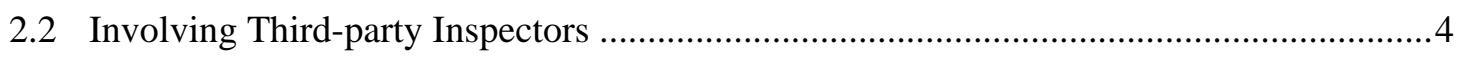

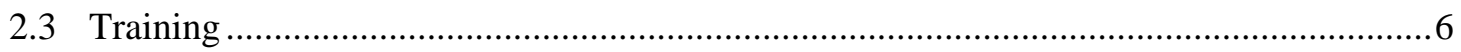

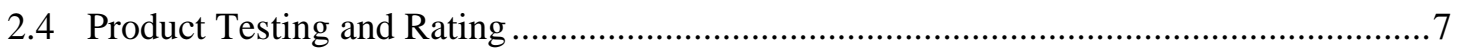

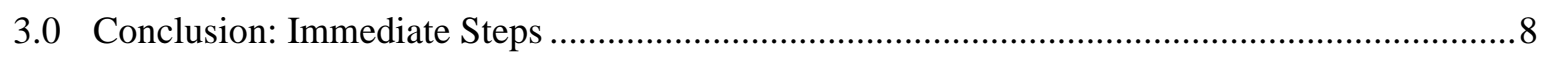

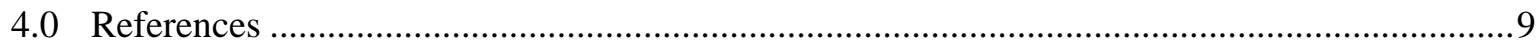

Appendix Key Findings from the Stakeholder Survey ….............................................................. 


\subsection{Background}

India launched the Energy Conservation Building Code (ECBC) in 2007, and the Indian Bureau of Energy Efficiency (BEE) recently indicated that it would move to mandatory implementation in the $12^{\text {th }}$ Five-Year Plan. The State of Rajasthan adopted the ECBC with minor additions; the new regulation is known as the Rajasthan Energy Conservation Building Directives - 2011 (R-ECBD). It became mandatory in Rajasthan on September 28, 2011.

The Rajasthan Renewable Energy Corporation Limited (RRECL), the State Designated Agency of the Bureau of Energy Efficiency in the State of Rajasthan, has developed an enforcement plan with the following elements:

1. Conduct ten one-day training sessions on compliance. Three training sessions were completed by December 2011, and RRECL is now working on three levels of trainings for professionals, code officials of urban local bodies (ULBs) ${ }^{1}$, and students and faculty members.

2. Develop capacity at the state and local levels. In the first two years, RRECL plans to establish a state-level review committee with technical experts and representation of ULBs and electricity distribution companies (DISCOMs). ULBs are expected to learn how to perform inspection and compliance checks in the first two years (i.e., 2012 and 2013) and to conduct a compliance check independently afterwards.

3. If BEE launches a national exam and certification system for third-party inspectors, the thirdparty inspectors could work with the ULBs to perform inspection. The state review committee would then focus its efforts on carrying out random checks and monitoring.

4. In the initial years, compliance checks are planned to be mandatory only at the design stage, and buildings will be randomly selected for inspection at the construction and pre-occupancy stages. Construction and pre-occupancy inspections could be mandatory when the capacity of third-party inspectors and code officials of ULBs are built.

5. Penalties for non-compliance are under development. Withholding the electricity connection and suspending the occupancy permit are two major options under consideration.

To understand the existing capacity and infrastructure of implementing R-ECBD in Rajasthan, the Pacific Northwest National Laboratory and the Malaviya National Institute of Technology Jaipur (MNIT), with support from RRECL and U.S. Department of Energy, hosted a stakeholder workshop in Rajasthan on October 13, 2011. The workshop, with 47 engaged stakeholders in attendance, included discussion of the implementation mechanism, training needs, and local market for energy-efficient products. This report provides recommendations on an R-ECBD enforcement roadmap for the State of Rajasthan, based on RRECL's enforcement plan listed above, local capacity, inputs from the workshop, and lessons learned from international experience of energy codes implementation. In addition, the Pacific Northwest National Laboratory and MNIT conducted a stakeholder survey in Rajasthan to understand stakeholders' opinions on ECBC compliance, training requirements, and perceived obstacles in ECBC implementation. Results and findings of this survey (included in the Appendix) could inform the Government of Rajasthan in the process of implementing and updating R-ECBD and designing training programs.

\footnotetext{
${ }^{1}$ ULBs, or local governments, are responsible for enforcement.
} 


\subsection{Proposed Implementation Mechanism}

\subsection{Institutional Framework}

ULBs will be responsible for R-ECBD implementation with a two-year interim period to build capacity. Third-party inspectors, if involved, could help expand capacity rapidly, but ultimately, ULBs will oversee the process and issue permits.

In the first two years (2012-2013), a state-level review committee could be formed with participation from RRECL, Public Works, ULBs, technical experts from other organizations such as MNIT, and DISCOMs (Figure 1). There should be at least one representative from each ULB. From 2014 and beyond, ULBs will enforce R-ECBD and conduct the compliance check. The state-level review committee will then conduct random checks and monitoring of ULBs' work on an annual basis. The state review committee should work as a facilitator and supervise code implementation including training, third-party inspections, and products testing and labeling. Advisory services could also be provided by the state review committee, including disseminating information about R-ECBD and energy-efficient products, establishing hotlines to answer technical questions, and developing online frequently asked questions (FAQs) and posting training materials online.

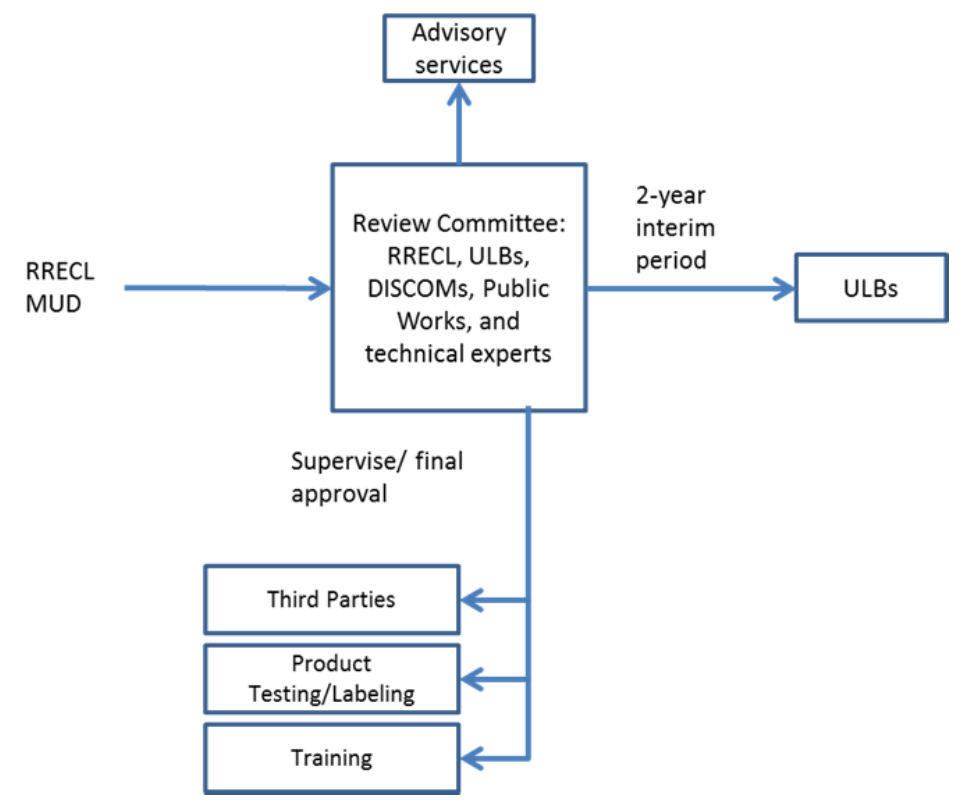

Figure 1. Proposed Roles of the State Review Committee

The compliance checks will be performed in two stages: plan review and site inspection during construction (Figure 2). In 2012, the state review committee will only do a plan review in this initial implementation phase; a list of documents required for plan review is shown in Figure 3. The state review committee could set a grace period for six months to encourage industry to learn about the new code and its enforcement. Buildings applying for permits could be randomly selected for construction inspection, 
and the number of buildings to be inspected could be maximized within the state's human and budgetary capacity. The construction inspection could be viewed as a learning opportunity in the early stages and more punitive in later years. In 2012 and 2013, no penalties will be issued for non-compliance during construction, but those responsible for the buildings will be asked to voluntarily correct errors until these buildings comply with the code; occupancy permits will still be issued for buildings not in compliance during the construction stage in 2012 and 2013. In 2014, ULBs will perform inspection checks independently, and the state review committee will randomly check the compliant buildings approved by ULBs; construction and plan review will be mandatory for all buildings. For non-compliant buildings, penalties could be issued at both the design and construction stages (Figure 2). If the design violates RECBD, the construction permit of the project will be suspended until the design complies with the code. If the building cannot pass the compliance check during the construction and pre-occupancy stages, the electricity connection and occupancy permit could be suspended until the building meets the R-ECBD requirements. Financial penalties can also be set up for noncompliance.

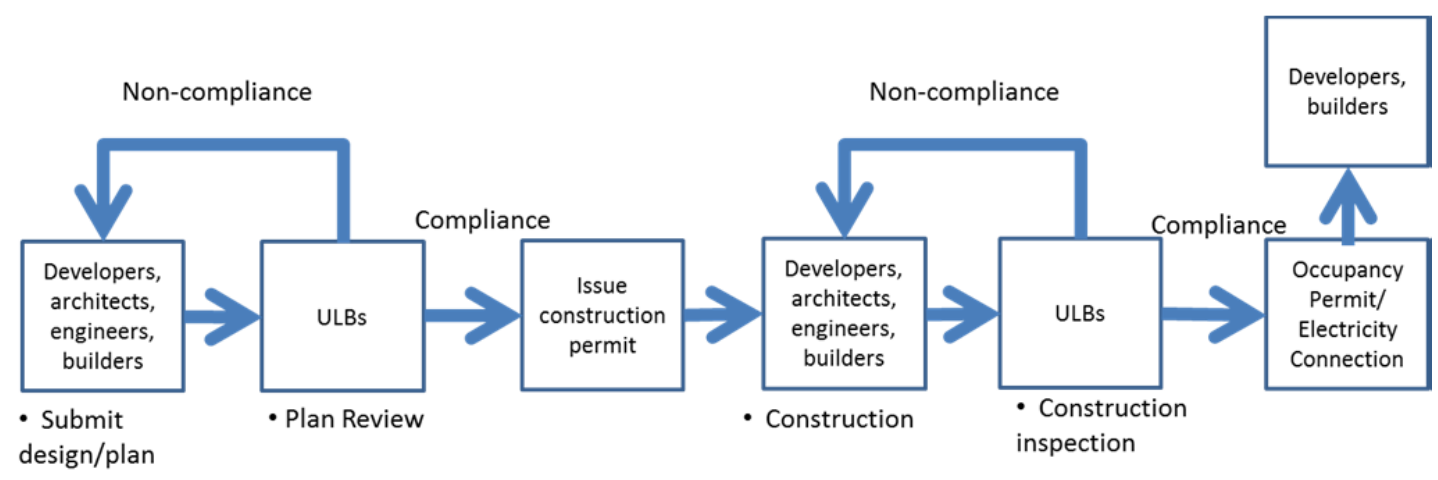

Figure 2. Compliance Checks and Penalties Under R-ECBD

Mandatory implementation provides regulatory incentive for stakeholders to understand and enforce energy codes. However, awareness enhancement and market penetration may take time, and stakeholders, especially developers, still have concerns and resistance to complying with R-ECBD. Thus, incentives could be considered in the first year of mandatory implementation (i.e., 2012) to encourage stakeholders adopting and complying with R-ECBD. Incentives such as relaxing zoning requirements and expedited project reviews do not require funding support from the enforcement agencies and thus are recommended. Other incentives such as rebate and fee reimbursements and income and property tax credits could be considered if necessary. After 2012, buildings that meet but do not exceed the compliance threshold generally will not be eligible for any special incentives.

\subsection{Involving Third-party Inspectors}

Given the limited capacity and human resources available in the state and local governments, involving third-party inspectors could rapidly expand the capacity for plan reviews and implementation more 
broadly. Carefully thinking through how to involve third-parties can guarantee a fair process. For example, there could be multiple checks and certification requirements for third-party inspectors, and the government should make the final approval when third-party inspectors are used in the project (Figure 3).

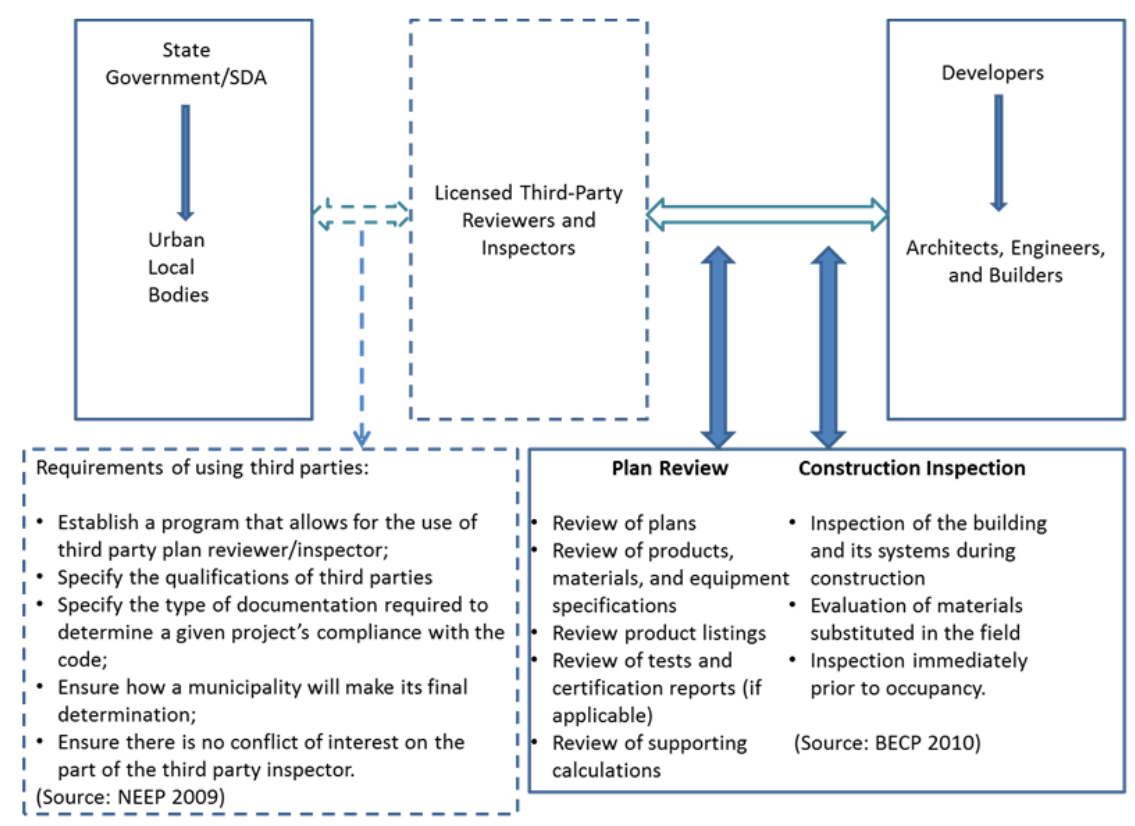

Figure 3. Third-party Involvement in R-ECBD Implementation

In addition, certain credentials are also required for third-party inspectors. BEE plans to eventually have a national exam and certification program, building from the existing certification program for energy auditors, but the timeline of developing the national certification program remains unclear. Alternatively, the state review committee could launch a state-level third-party system. There are international precedents for such local and state-level third-party certification, for example, in the United States.

Licensed architects and/or energy auditors who complete a two-day training on R-ECBD and compliance check could serve as third-party inspectors with a temporary state certificate and be directly hired by developers. ULBs will perform random checks on projects approved by third-party inspectors. If a project that has been inspected by a third party is, in fact, not compliant with R-ECBD, the certificate of the third-party inspector could be revoked, and developers could be fined with fees or an extended project review period, in addition to receiving non-compliance penalties. Of course, this implies that ULBs also have the capacity to check plans and buildings.

Setting up a third-party inspection process will take some time unless Rajasthan enlists the services of other organizations (e.g., the National Productivity Council) to do this. Developing a third-party system will involve:

1. Convening a certification exam committee to oversee the development of the examination 
2. Performing a job task analysis to determine what knowledge inspectors must have and in which part(s) of the code they will need to become experts

3. Developing a question bank that will be used to develop certification exams; note that certifications for plan review and inspection will be different

4. Developing and administering the exams.

Third-party inspectors should meet minimum qualifications to ensure they have enough understanding of building energy efficiency and R-ECBD. Another minimum qualification would be to require all inspectors to be licensed architects or engineers or to have an undergraduate degree in a constructionrelated field. This would ensure that the applicants have at least a basic understanding of construction and buildings.

Although setting up the exam and certification process will be time-consuming, training is an integral part of any implementation mechanism. The recommendations below highlight potential options for training to develop an effective and rigorous third-party system.

\subsection{Training}

A three-tier training program could be designed for different stakeholder groups with different foci, thus raising awareness, enabling inspection, and providing more technical details for advanced audiences. The state plans to carry out ten training sessions. As such, the state review committee could list training sessions and descriptions on RRECL's or MNIT's website, and advisory services discussed above could be established to support training.

The ten planned training sessions could serve as the first phase of overview training. The next phase of training could directly focus on those involved in the design, construction or enforcement of R-ECBD. A curriculum can be developed for particular target audiences in mind. For example, those conducting plan reviews can be provided with training on how to plan review for the ECBC; those focused on design could receive training on how to design to and demonstrate compliance with the ECBC, etc. The third phase of training would be to visit architectural and engineering offices or attend monthly/quarterly architectural/engineering association meetings and provide short localized sessions (e.g., brownbag presentations) on certain elements of the energy code that may be problematic.

To build capacity on plan review and construction inspection, ULBs may need both classroom training and field training. The state review committee could also set up an apprentice program in which someone who wants to be an inspector "shadows" an inspector to learn how to do this.

Providing technical support and building a feedback loop are essential for a rigorous training program. It is important to set up the ability to have questions answered by both industry and from organizations in charge of code enforcement. This can be a university or someone who is deeply knowledgeable on the code and on how it will be implemented. This could also help the state review committee to gather information of problem areas in the code that can be the focus of further educational efforts. 


\subsection{Product Testing and Rating}

Product testing and rating is important to facilitate code enforcement. It could provide developers and designers with reliable information on component efficiency, allow inspectors to easily check if components match design, and encourage manufacturers to produce high-quality products. Without any testing facility in Rajasthan at present, the state review committee could start to collect data on products and build a product directory with the following information: estimated thermal conductance (U-factor) and other physical properties, efficiency of different building components (e.g., HVAC equipment efficiencies, light source efficacies, fenestration solar heat gain coefficients, etc.), manufacturers, and installation instructions. The product directory could provide information in the early stages. As codes are implemented and testing facilities are formed, the state may require that only products listed in the directory will be installed in buildings. In the United States, for example, California issues and updates information for insulation materials annually, and only materials on the list are allowed to be used in buildings.

The product directory could provide reference for developers, architects, and inspectors. Developing a product testing and rating system may take time and effort. In lieu of a product testing system, the state could also refer to case studies, default tables of U-values ${ }^{1}$, an existing database of CEPT University and/or ECO-III Project, and require detailed specifications of products. In addition, the state could provide incentives to encourage product testing and labeling in the testing facility at CEPT. In the long term, the Rajasthan state government could also take steps to encourage the manufacture of energyefficient building materials. Measures that may help to stimulate manufacturers to begin systematic testing of their products include: soft loans or low-interest loans, tax benefits, and special economic zones.

\footnotetext{
${ }^{1}$ Default tables of U-values usually contain only a few simple options and do not include elements that are difficult to inspect in the field. The Washington State Energy Code includes default tables of various building components. For example, Section 1006 of the Washington State Energy Code specifies default U-values for glazing and doors (http://apps.leg.wa.gov/wac/default.aspx?cite=51-11-1006).
} 


\subsection{Conclusion: Immediate Steps}

There are a few immediate steps that RRECL could take to build capacity and facilitate R-ECBD implementation:

1. Incorporate R-ECBD specifications in existing building bye-laws. ULBs will be responsible for R-ECBD implementation; including R-ECBD in building bye-laws will provide regulatory support. In the long term, the Department of Urban Development and Housing, which supervises ULBs, could oversee implementation, while RRECL would provide technical support and policy interventions.

2. Form a collaborative state review committee, and launch a clear regulatory framework for R-ECBD implementation. The committee could have representation from both the building industry and regulatory industry. Having a practicing architect and engineer on the committee would be beneficial. This committee would have an advisory role and help in implementing the code. This structure has been used in Idaho in the United States and proved extremely successful in getting the code into place.

3. Develop training and educational programs. This is going to be critical to getting the code implemented. Training will need to be ongoing (i.e., multi-year). As discussed above, a threetier system starting with basic training and going toward more advanced are highly recommended. It is also essential to include energy code training as part of professional licensing requirements.

4. Build access to technical assistance. Hotlines and FAQs could be helpful to build capacity and gather information. Technical write-ups like tip sheets, technical brochures, and user guides could also provide code interpretation and assist the end users.

5. Set up a third-party inspector system and plan review. Third-party inspectors, if involved, could help expand capacity rapidly; but ultimately, ULBs will oversee the process and issue permits.

6. Develop a pilot project to test and document R-ECBD implementation. Have a camera crew filming code compliant installations of all the features that are going into the building, if possible. This can be used for future videos for inspection, and the pictures can be put into training materials for future use. Depending on the time frame of the project, this pilot project can also be a great classroom for inspector training in the short term.

7. Prepare for better implementation. Some procedures are essential to code implementation but expensive and time-consuming. The State of Rajasthan could collect information for these issues even at the early stage of code implementation: product directory, product testing and labeling, and measurement of compliance. 


\subsection{References}

Northeast Energy Efficiency Partnerships (NEEP). 2009. Effective Use of Third Party Inspectors for Enforcing the Building Energy Code.

http://neep.org/uploads/NEEPResources/id203/Third\%20Party\%20Inspection\%20White\%20Paper.pdf, May 2011 (accessed).

U.S. Building Energy Codes Program (BECP). 2010. Building Energy Codes 101 Training Manual. http://www.energycodes.gov/becu/documents/BECU_Codes_101_Training_Manual.pdf, June 2011 (accessed).

Washington State Building Code Council. 2010. 2009 Washington State Energy Code. https://fortress.wa.gov/ga/apps/sbcc/Page.aspx?nid=14 , December 2011 (accessed). 



\section{Appendix}

\section{Key Findings from the Stakeholder Survey}

To understand stakeholders' capacity and their knowledge on the Energy Conservation Building Code (ECBC), the Pacific Northwest National Laboratory and the Malaviya National Institute of Technology Jaipur conducted a survey among various stakeholder groups (i.e., architects, engineers, builders, construction managers, specialized contractors, and material suppliers). The results and findings of this survey could inform the Government of Rajasthan in the process of implementing and updating building energy codes and designing training programs. We received 39 completed questionnaires, and the key findings are summarized below.

1. Understanding of ECBC. The majority of stakeholders rated their knowledge of ECBC as knowledgeable (38\% very knowledgeable and 46\% somewhat knowledgeable). Stakeholders almost exclusively recognized the value of ECBC. Financial savings, energy savings, thermal comfort, and reduction of $\mathrm{CO}_{2}$ emissions were listed as key values. Less than $10 \%$ of respondents pointed out that they were concerned about additional investment and lack of awareness.

2. ECBC compliance. More than $80 \%$ of respondents agreed that they understood ECBC requirements and how to comply with it in design and construction. The building envelope was listed as the most difficult component to comply with the code, followed by heating, ventilation and air conditioning; service hot water and pumping; electric power; and lighting. When asked if they were familiar with different code compliance approaches, a quarter of interviewees did not respond. Half of the respondents admitted familiarity with all three code compliance approaches (prescriptive, trade-off, and whole building performance).

3. Obstacles for ECBC implementation. Lack of training on the code was considered the most important barrier for code implementation, followed by perceived cost, lack of developer/consumer awareness, lack of support by state/local officials, lack of available information on the code, lack of availability of qualifying products, and designers not specifying to codes. Most perceived obstacles are institutional and awareness issues. Less than $10 \%$ of the respondents were concerned about the complexity of codes and increased workload by complying with the code. Creating awareness, policy intervention, and availability of material and code information were listed by respondents as main measures to increase code compliance in their respective communities.

4. ECBC training. Half of the respondents had attended ECBC training sessions. In terms of training format, classroom training was dominantly preferred, and about $23 \%$ and $14 \%$ of respondents, respectively, said they would like to attend onsite training and webinars.

Accordingly, respondents felt that the training workshop would be more useful than other learning mechanisms such as brownbag lunch presentations, a website, and an email listserv. Survey respondents were most interested in training on general knowledge of the energy code, building envelope, lighting/electrical, and software trainings. 